\title{
Control strategies comparison of a ventilated facade with PCM - energy savings, cost reduction and $\mathrm{CO}_{2}$ mitigation
}

\author{
Alvaro de Gracia ${ }^{1}$, Reza Barzin², Cesar Fernández ${ }^{3}$, Mohammed M. Farid ${ }^{2}$, Luisa F. \\ Cabeza ${ }^{4, *}$ \\ ${ }^{1}$ Departament d’Enginyeria Mecanica, Universitat Rovira i Virgili, Av. Paisos Catalans 26, 43007 \\ Tarragona, Spain \\ ${ }^{2}$ Department of Chemical and Materials Engineering. The University of Auckland, Auckland, New \\ Zealand \\ ${ }^{3}$ Computer Science Department, University of Lleida, Lleida, Spain \\ ${ }^{4}$ GREA Innovació Concurrent, Universitat de Lleida, Edifici CREA, Pere de Cabrera s/n, 25001, Lleida, \\ Spain. \\ *Corresponding author: Tel: +34.973.00.35.76. Email: lcabeza@diei.udl.cat
}

\begin{abstract}
The use of active thermal energy storage can provide energy savings, cost reduction and $\mathrm{CO}_{2}$ mitigation by reducing energy demand for heating and cooling, allowing the use of peak load shifting strategies and enhancing the introduction of renewable energies in the sector. The high investment cost of these systems makes mandatory an appropriate control in order to maximize the energy benefits during its operation. Within this context artificial intelligence techniques have been successfully used to control active thermal energy storage units. This paper uses an experimentally validated numerical tool to study the effect of different control strategies on the performance of one TES system applied to the building sector, a ventilated facade with PCM which uses free cooling. Three different strategies were designed to control the ventilated facade based on cost savings, energy reduction and $\mathrm{CO}_{2}$ mitigation, under different climatic conditions. Results show robust benefits in the three tested control strategies, achieving average savings in comparison to a manual operation of the system of $4.3 \%, 7.8 \%$, and $16.7 \%$. Moreover, the paper shows that when the control strategy is focused on optimizing cost, the other two benefits claimed by TES systems (energy and $\mathrm{CO}_{2}$ mitigation) are significantly reduced.
\end{abstract}

Keywords: thermal energy storage (TES); phase change materials (PCM); artificial intelligence; control system; $\mathrm{CO}_{2}$ mitigation 


\section{Introduction}

High consumption of fossil fuels in the past two decades and excessive $\mathrm{CO}_{2}$ emissions have resulted in significant environmental problems all over the world. Problems such as global warming climate change and the depletion of the ozone layer have made governments, scientists and policy makers in the developing and developed countries search for a solution to address this problem [1]. Buildings are responsible for $40 \%$ of global energy consumption, which contributes to production of up to $35 \%$ of green house gases in European Union. [2]. An increase of 50\% in global energy demand is expected between 2008 and 2030 [3]. This shows the significance of energy consumption in buildings. A reduction in building energy demand can significantly reduce the total energy consumption in buildings as well as production of green house gasses $[4,5]$.

The useful renewable energy resources such as solar heating, PV (photovoltaic) and wind turbines also can result in high energy saving and $\mathrm{CO}_{2}$ emission reduction. However, due to the intermittent nature of these energy resources their availability might not match the demand. For instance, the peak of solar irradiation occurs during the day, when the heating demand is low and the highest demand occurs during the night when there is no solar irradiation [6].

In certain periods of the day, electricity users consume more electricity compared to other periods of the day, which is known as peak load period. Supplying sufficient amount of electricity to meet the demand puts pressure on the power plants. Moreover, electricity generation during this period is less inefficient and results in higher carbon emission.

Peak load shifting is a load management technique that aims to move demand from the peak hours to off-peak hours of the day. The electricity providers generally use variable price scheme (low price during the off peak period and high price during the peak period) in order to encourage the electricity consumers to use electricity during the lowpeak period of the day and reduce their electricity consumption during the peak period. 
Thermal energy storage (TES) materials can be used in order to store heat or cold during off-peak periods to be used during the peak period [7, 8]. Phase change materials (PCM) offer a good thermal storage due to their high storage density, which make them suitable for energy storage applications $[9,10]$. There are many reported studies on the use of PCM in buildings in both active [11] and passive systems [12]. An active system refers to storage systems in which an additional fluid loop is used to charge and discharge the stored energy to supply heating or cooling. On the other hand, a passive system does not involve any additional heat exchanger. Chilled water tanks and ice storage tanks are one of the most common active TES equipment [13]. Underfloor heating with PCM and PCM wallboards are examples of passive systems [14].

Various thermal storage techniques have been used in combination with variable electricity price scheme in order to both minimize the electricity cost and perform peak load shifting. For instance [15] used thermal mass of the building (as sensible heat storage) to store cold through precooling in summer. They used day-ahead real time electricity rates and used optimal control to minimize the cost. Using a global minimization algorithm, they performed simulation studies for different climates and they achieved a cost saving of $0-14 \%$ depending on the building, climate and characteristics of the rate signal. This method demonstrated through simulation [16], lab scale measurements [17] and field studies [18].

However, this is not possible in lightweight buildings as these buildings have little thermal mass. As a result, latent heat thermal storage was suggested to store energy during the off peak period for use during the high peak consumption period. Kummert et al. [19], used optimal control theory, building model forecasted electricity price to minimise a given cost function over the optimisation horizon. This cost function could also combine comfort level and energy consumption. In a similar study, Dehkordi and Candanedo [20], have used model predictive control (MPC) algorithm designed using time-dependent electricity price profile. They used ice storage for thermal energy storage and achieved a total saving of $23 \%$ over the period of simulation. In a similar study, performed by Sehar et al. [21] and using ice storage, they achieved 27-31\% saving for different climates of United States. Different optimal control strategies and algorithms were also developed for improving the performance of the ice/water storage 
systems [22, 23]. However, most of these optimal controls are developed based on dayahead electricity prices and operation arrangement.

A limited number of studies have been reported on the application of PCM in combination with variable electricity price scheme to minimize the electricity cost. The main focus of previous studies has been on the development of a suitable PCM storage and the study of its application in various ways in building envelopes.

In 2011 a research group at The University of Auckland, New Zealand, proposed the application of variable online electricity price in combination with PCM (as passive latent heat storage) in order to reduce electricity cost while performing peak load shifting. They used DuPont wallboards in a test hut and experimentally showed that using the proposed method a cost saving of 26.7\% (20-30\%) can be achieved [24]. They also used the same price-based method for combination of PCM impregnated underfloor heating and DuPont wallboards resulting 28.7\% cost saving [25]. To further increase the savings they also employed night ventilation in summer and weather forecast in winter in combination with the price-based method resulting to a significant cost saving of $67 \%$ and $40 \%$ was achieved [26, 27].

The system used as a case study in this paper consists of a ventilated facade with PCM in its air chamber. A previous study has optimized the control of such active TES system using reinforcement learning techniques based on maximizing energy benefits [28]. However, this paper compares the performance of this system when applied to the building sector, and optimized based on cost, energy reduction, and $\mathrm{CO}_{2}$ mitigation, showing the potential of TES systems and the ability of this control algorithms to be adaptable to provide different outcomes. Moreover, the paper shows how optimizing based on one output can influence the other two benefits claimed by TES systems. 


\section{Methodology}

\subsection{Operating principle and numerical model}

A ventilated facade with PCM in its air chamber is used as a case study to evaluate the influence of different control strategies based on reinforcement learning techniques in the performance of a TES active system. The system uses low temperatures at night to solidify the macro-encapsulated PCM (CSM panels of 450x300x10mm filled with RT21 from Rubitherm [29]) installed in the cavity and provides a cooling supply once is required by the demand. The PCM is distributed inside the cavity forming 14 channels, as shown in Figure 1.

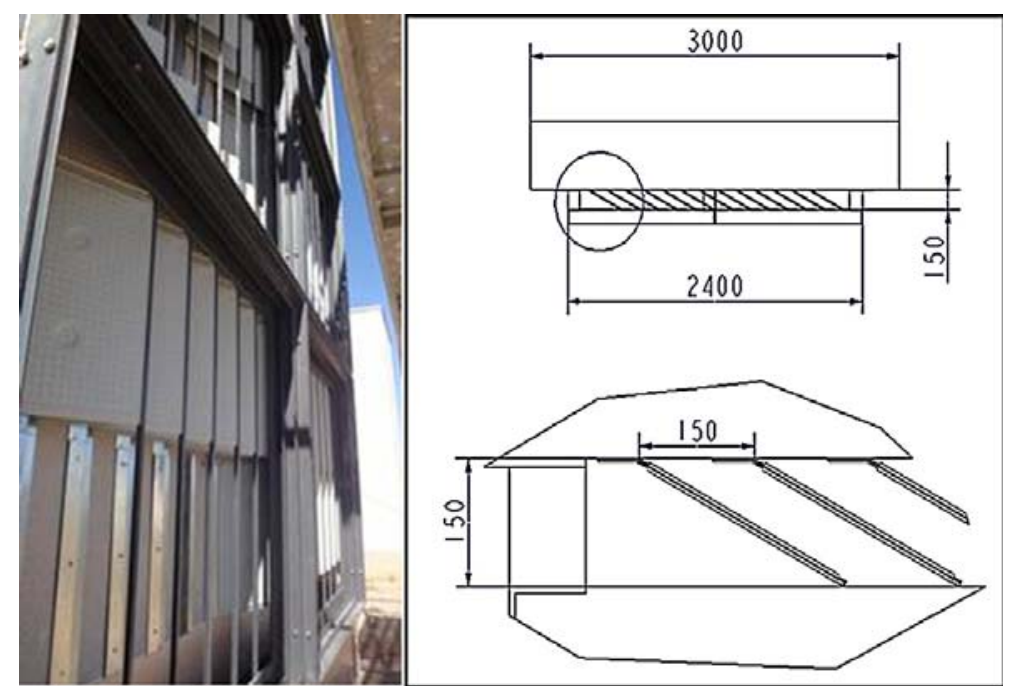

Figure 1. PCM panels distribution inside the ventilated facade air chamber

This system has been experimentally tested [30] being equipped with six automatized gates to control airflow path, and with fans $(52.5 \mathrm{~W})$ at the bottom of the channel so mechanical ventilation can be supplied. The sequence of operation starts with the charge process (Figure 2a), which occurs during nighttime if the outer temperature is lower than the temperature of the PCM. Once the PCM has been fully solidified, the fans are stopped and all the gates are closed during the storage period (Figure2b). Finally, once required by the demand, the cold stored is discharged to the inner environment as shown in Digure2c. The cooling supply will avoid or reduce the use of other cooling system such as heat pumps, and the related electrical energy consumption. However, it has to 
be noticed that in both charging and discharging process the use of mechanical ventilation is required, so an electrical consumption of the fans is produced. The consumption of the fans as well as the savings provided during the cooling discharge have to be taken into account when analyzing the energy, cost and $\mathrm{CO}_{2}$ emissions balances of the system, and the optimal control of this technology plays a crucial role.

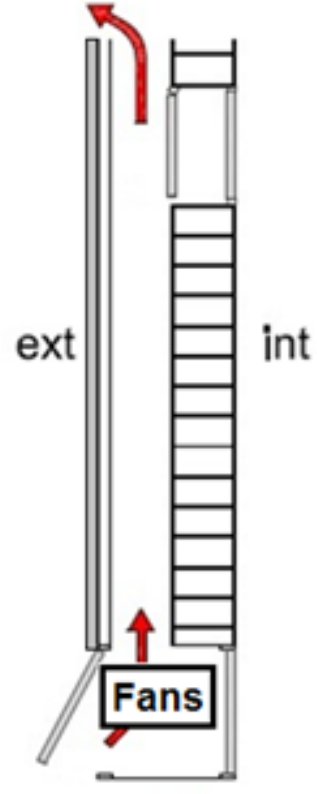

(a)

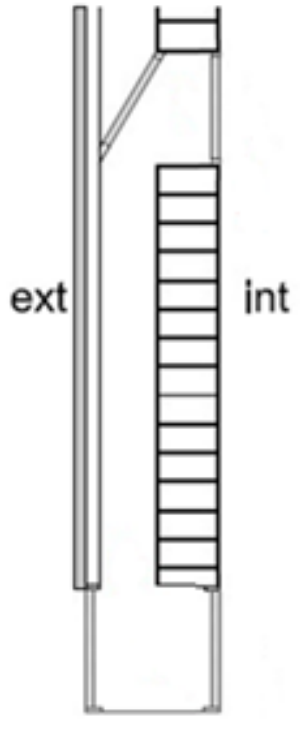

(b)

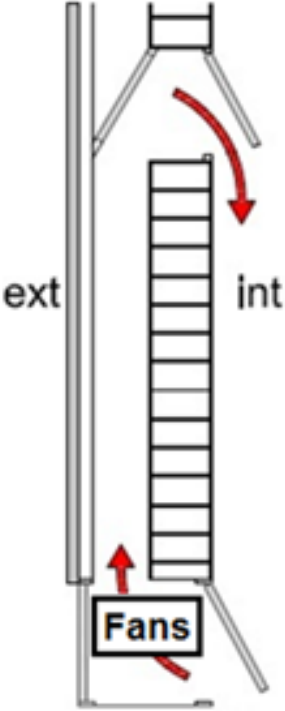

(c)

Figure 2. Sequence of operation. a) Charge process, b) Storage period, c) Discharge process

The performance of the system is very sensitive to the outdoor night temperature, since it defines the potential for PCM charging. Hence the control of the system have to be optimized for each conditions based on a daily weather prediction in order to make use of fans as minimum as possible. Reinforcement learning techniques will be applied to define the control of this active thermal energy storage system, these techniques required several number of cases and scenarios to determine the best control strategy. A simple non-iterative numerical model has been used to feed the reinforcement learning algorithm. The numerical tool assumes that all the PCM installed in the facade is at the same temperature and its phase change is considered using the equivalent heat capacity curve [31]. Moreover, in order to quantify the heat transferred during the charging and discharging processes between the PCM and the air flow, fully developed internal flow is considered inside each of the 14 air channels showed in Figure 1. In addition, heat 
losses to the environment are taken into account during the storage periods. The simple model is suitable to feed the reinforcement learning algorithm, since it does not require iterative solvers, and has been experimentally validated showing good accuracy with deviations below $\pm 3 \%$ [32]. Moreover, it has to be noticed that the model can only be applied to systems using PCM without subcooling, hence similar melting and solidification temperatures are required.

\subsection{Reinforcement learning}

Optimal control of real systems arise in several forms, ranging from control of cooling and heating systems to scheduling complex managing operations. These problems are solved by iterating the process of taking decisions and observing the effects, being called sequential decision problems. In this sense, Dynamic programming [33] has been a traditional tool to solve sequential decision problems through the well-known Bellman equations, but problems with a high number of variables, decisions and states, make inefficient classical approaches. Smart searching strategies overcome this dimensional problem avoiding the complete search of dynamic programming algorithms. Reinforcement learning [34] is an example of such new techniques, modeling the system as a set of states and actions. At each state, one can take an action, obtaining a given reward and leaving the system at a new state. In this particular case, the system state is only determined by the PCM temperature, using gradient descent methods to overcome the problem of having an infinite number of states. The set of actions consists in not activating the ventilators or activating them at a set of determined speeds. The amount of thermal energy obtained from the PCM (reward) minus the investment in the form of electrical energy consumed by the ventilators is maximized. Furthermore the cost and $\mathrm{CO}_{2}$ emissions associated to these rewards and investments are computed when optimizing based on cost and $\mathrm{CO}_{2}$ mitigation.

Under these considerations, the model considered in this paper is deterministic, in other words, a perfect foresight is always expected. As there is no uncertainty, one can employ the classical Bellman formulation to solve it. We refer to de Gracia et al. [28] for a detailed description of the optimization model as well as the algorithmic approaches. 


\subsection{Control strategies}

As it was previously stated, different control strategies will be applied to control the operation of the ventilated facade with PCM. These control strategies will optimize timing and distribution of the charge, storage and discharge processes in order to maximize the benefits in terms of net electrical energy, cost and $\mathrm{CO}_{2}$ emissions savings. The different control strategies are programmed to determine the operation of the system every 15 minutes.

In case of optimizing net electrical energy savings, the system requires an electrical energy investment for charging and discharging of the PCM since mechanical ventilation is required (fans) to ensure solidification and melting. The reward is quantified using the cooling supplied by the system to the indoor environment, which is converted from thermal energy to electrical energy using a ratio of 3 , simulating a standard air conditioning equipment with $\mathrm{COP}=3$. The control system determines the charging and discharging process. The discharge is always programmed to start after 10:00 a.m. until the corresponding cooling provided by the storage system does not compensate the electrical consumption of the fans. Moreover, the system controls the charging process selecting the most appropriate timing according to weather conditions so it can optimize the investment in form of use of the fans.

The cost of electricity at each hour in summer is introduced in the optimization algorithm when the control system is programmed to maximize cost savings. In this case, the system does not only take into account the weather conditions, but the cost of electricity to determine whether to activate the fans or not. The cost of electricity is considered both in the investment (fans operation) and reward (electrical energy associated with cooling supply). The distribution of electricity cost was computed daily according to the Spanish tariff 2.0A [35].

Finally, the energy consumption and savings provided by the system were linked to the corresponding $\mathrm{CO}_{2}$ emissions. The amount of $\mathrm{kg}$ of $\mathrm{CO}_{2}$ emitted to the atmosphere per $\mathrm{kWh}$ varies significantly depending on the one hand on the use and availability of 
renewables, and on the other hand on the electricity production based on fossil fuels. The distribution of the Spanish energy mix during 2012 was registered at 4 hours interval according to Red Eléctrica Corporación S.A. [36] and grouped into the following categories: nuclear, coal, combined cycle, wind, PV, hydraulics, and special (cogeneration and others). Each source for electrical energy production has its corresponding emission factor ( $\mathrm{g} \mathrm{CO}_{2} / \mathrm{kWh}$ ), as shown in Table 1 [37]. The data was then interpolated according to the used time step in the control algorithm (15 minutes).

Table 1. Emission factor for each technology used for electricity production in Spain

\begin{tabular}{lc} 
Technology & $\begin{array}{c}\text { Emission factor } \\
{\left[\mathrm{g} \mathrm{CO}_{2} / \mathrm{kWh}\right]}\end{array}$ \\
\hline Coal & 1039 \\
Combined Cycle & 390 \\
Wind & 0 \\
PV & 0 \\
Hydraulics & 0 \\
Special & 269
\end{tabular}

The performance of the three described control strategies will be compared against a manual operation of the system in order to quantify the benefits of controlling this kind of active storage systems according to the different objectives. The manual mode is programmed to charge the storage from 04:00 to 06:00 am, and to discharge the cooling supply at 10:00 am.

\subsection{Worldwide impact of different control strategies}

The performance of the ventilated facade is very sensitive to weather conditions; hence the control system has to adjust the operation of the ventilated facade to maximize the benefits under different conditions. For this purpose, the performance of the previously defined control strategies were analyzed when operating under different climatic conditions as defined in Köppen-Geiger climate classification [38]. Cities from all possible climates with cooling needs were selected, and its outdoor temperature were obtained from EnergyPlus Weather Database [39] from June $21^{\text {st }}$ to September $22^{\text {nd }}$ in 
case of cities located in north hemisphere, and from December $21^{\text {st }}$ to March $20^{\text {th }}$ for the selected cities from the south hemisphere.

The authors want to highlight that in this paper, costs and $\mathrm{CO}_{2}$ emissions were considered according to Spanish electricity system even when analyzing the performance of the ventilated facade with PCM in other countries. Therefore, a more accurate evaluation of cost and $\mathrm{CO}_{2}$ emissions would require the analysis of electrical energy production of each country, which is out of the scope of this work, focused on highlighting the potential of different control strategies, and demonstrating how the optimization based on a certain objective can influence the rest of possible outcomes from a certain active heat storage technology.

\section{Results and discussion}

\subsection{Performance of the system operating with different control strategies}

This section will present the effect of using control strategies based on the previously defined reinforcement learning techniques in the performance of the active TES system. Figure 3 shows the net energy savings achieved by the system in the different analyzed climates when controlled according to artificial intelligence techniques (automatic mode) and controlled manually, as described in Section 2.3. The results demonstrate that the control algorithm enhances the net energy savings in all climates, increasing the benefits in climates which are suitable for the operation of the technology (Warm temperate and Snow) and avoiding waste of energy in Equatorial and Arid climates.

Similar results were achieved in de Gracia et al. [28] even though using different time step for control decision (having increased it from 10 to 15 minutes in this research for computational resource reasons). The use of automatic mode improves averagely $4.3 \%$ the energy savings when implemented in climates which are proved to have potential for the operation of the system (energy savings higher than $1 \mathrm{MJ} /$ day), 


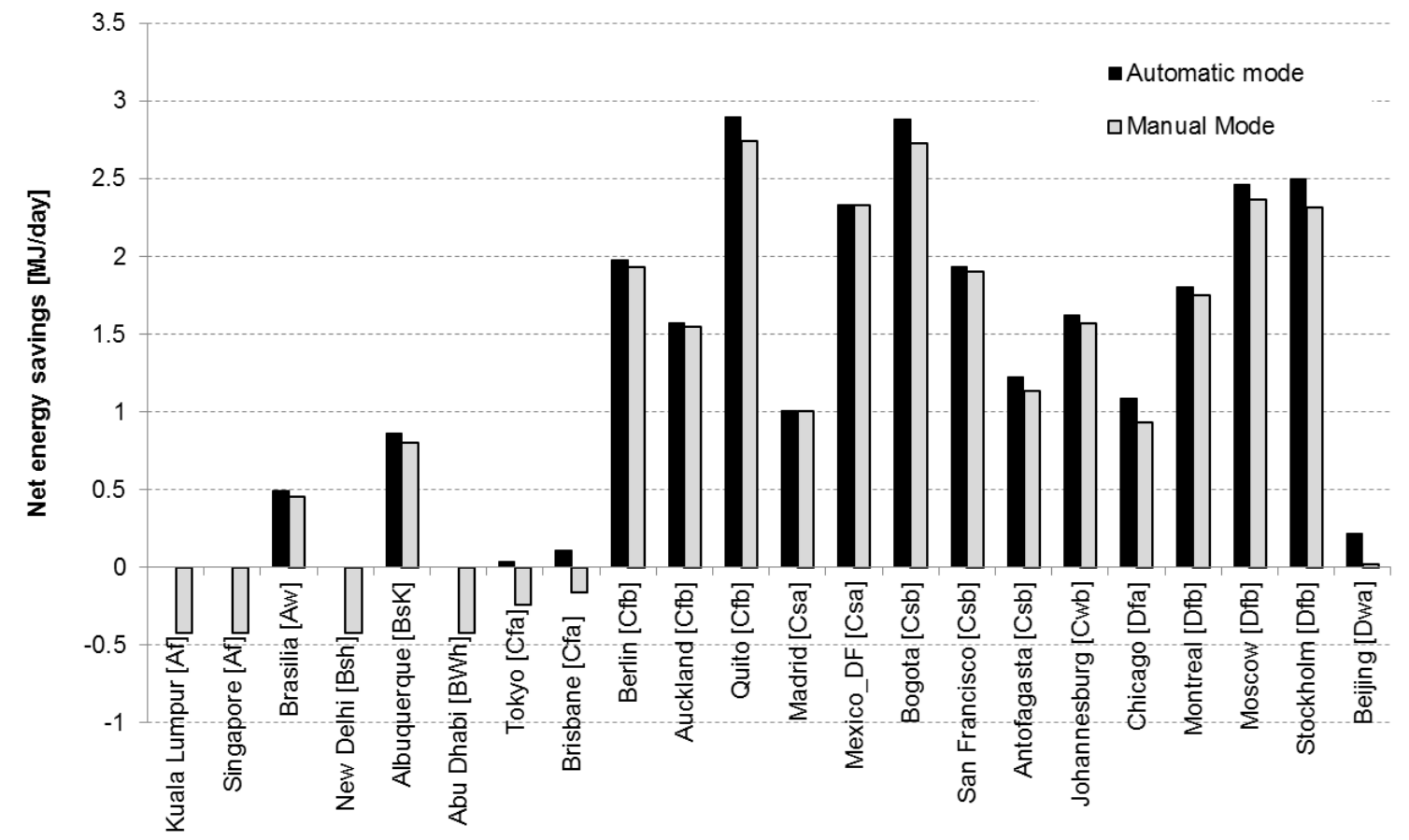

Figure 3. Net energy savings provided by the system in automatic and manual mode

Similar patterns can be found when comparing the system using manual and automatic control mode based on cost, as shown in Figure 4. The average benefits on cost basis due to the use of the automatic mode are $7.9 \%$ in climatic regions where the use of the ventilated facade with PCM is suitable. Furthermore, it can be noticed that the influence of the automatic mode differs depending on the climate, having significant average savings in cities such as Chicago (14.6\%) and negligible benefits in cities such as México D.F. (3.2\%). This fact can be explained due to the variability of the weather conditions, showing that the automatic mode can adapt the operation of the system according to daily specific weather conditions. 


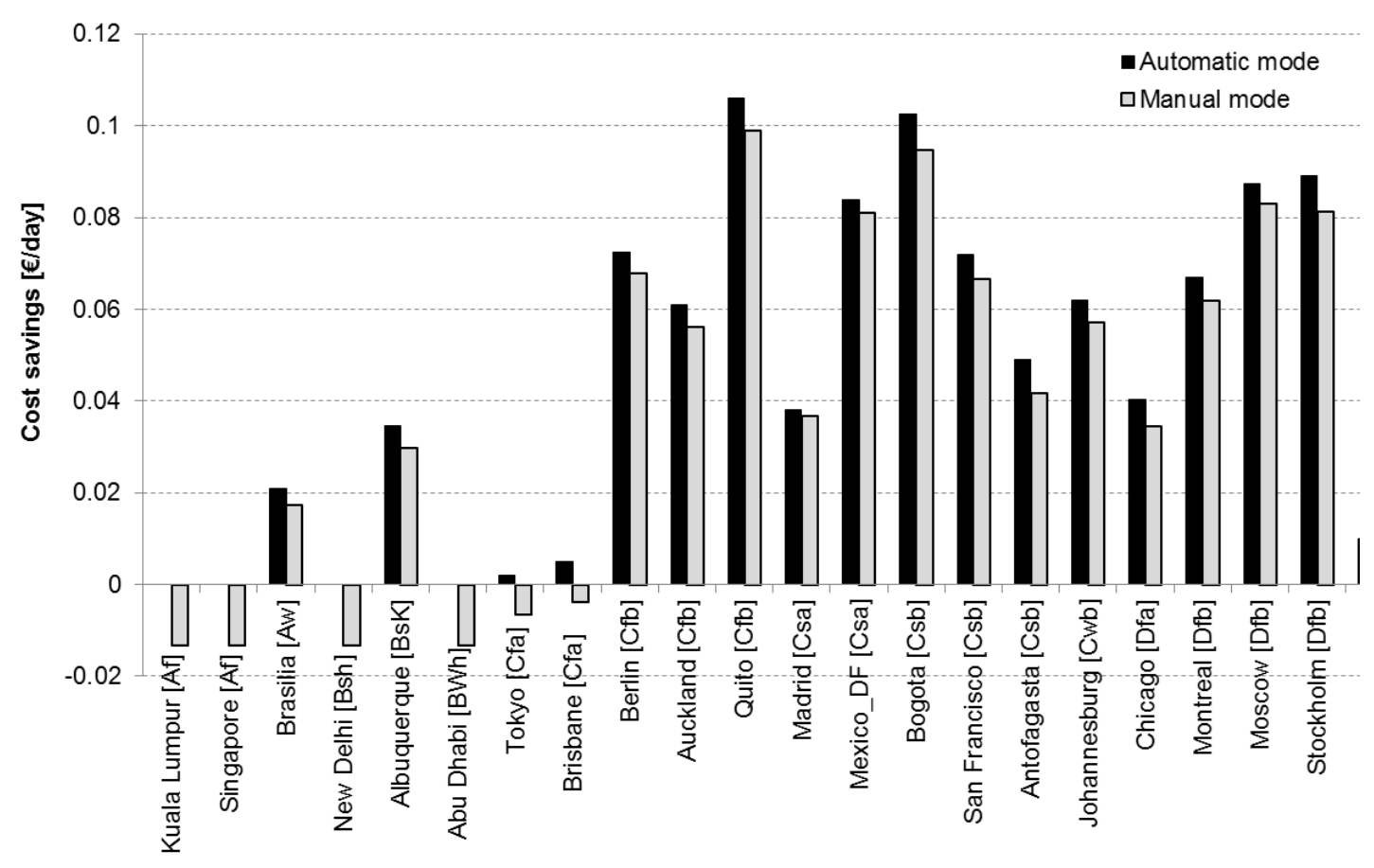

Figure 4. Cost savings provided by the system in automatic and manual mode

In addition, Figure 5 presents $\mathrm{CO}_{2}$ mitigation achieved by the system when operated according to automatic and manual modes. Here, the difference is higher than the improvements achieved in the control strategies programmed to optimize energy and cost, especially in Quito (Cfb), Johannesburg (Cwb), and Antofagasta (Csb) since the suitable outer conditions for PCM charging during night are available during more hours, and hence the control can decide in a wider range the charging according to the a more sustainable energy mix. The average improvement achieved by the automatic system is $16.7 \%$, when it is used under suitable climates for the operation of the system. As occurred in the energy and cost cases, in the climatic areas where the system cannot provide benefits, it avoids the waste of $\mathrm{CO}_{2}$ emitted to the atmosphere. 


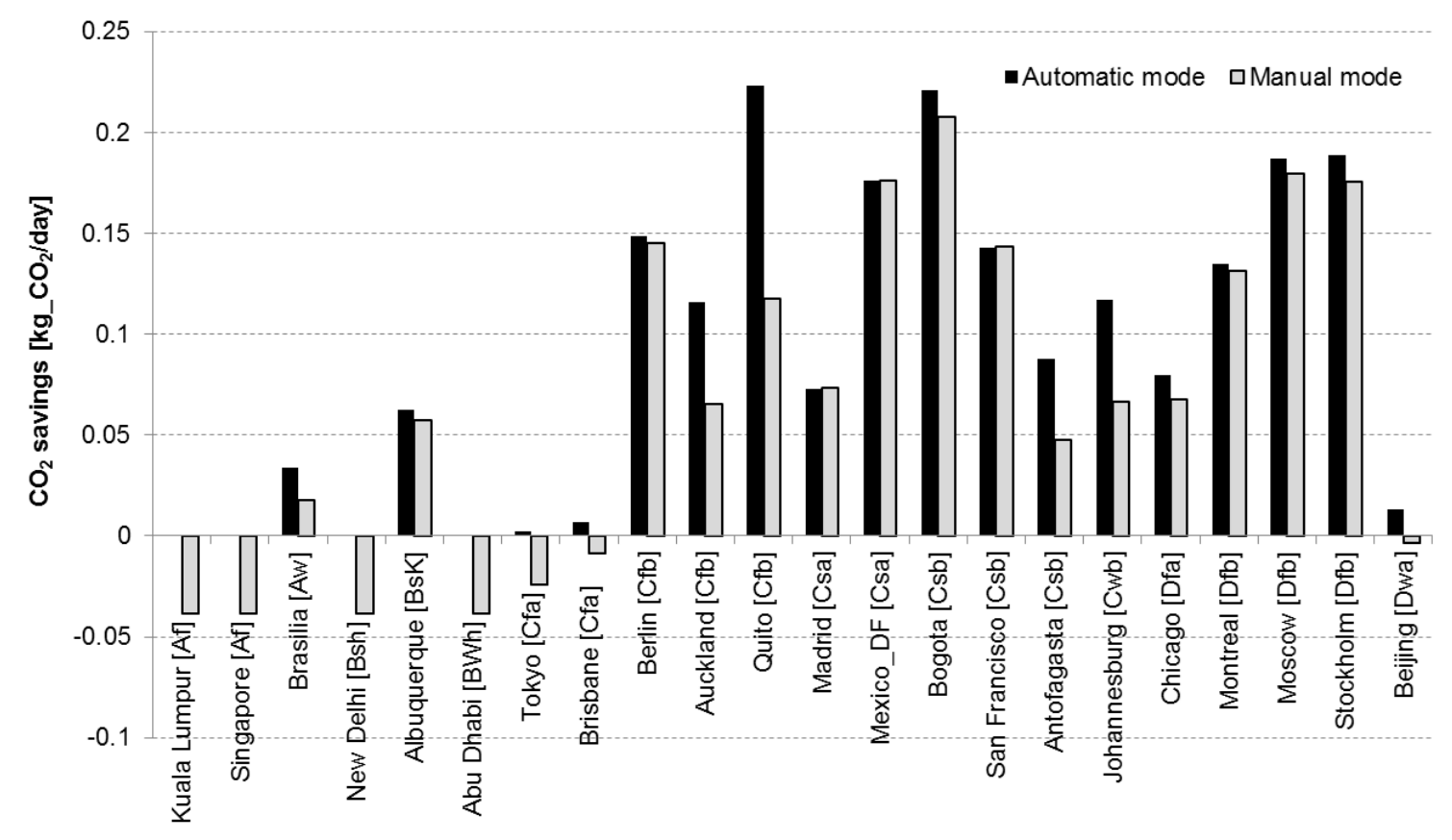

Figure 5. $\mathrm{CO}_{2}$ mitigation provided by the system in automatic and manual mode

\subsection{Influence of each control target on the other outcomes}

In the previous section, the benefits achieved by the system when it is controlled based on optimizing a specific outcome (energy reduction, cost saving and $\mathrm{CO}_{2}$ mitigation), however, no information was provided regarding how this optimization influences the other two outcomes provided by the system. Figure 6 presents the variation of the different outcomes in respect to its optimum when optimizing based on any other objective. In this sense, Figure 6a shows how cost savings and $\mathrm{CO}_{2}$ mitigation are reduced when the system operates at maximizing energy savings, Figure 6b presents the reduction in energy savings and $\mathrm{CO}_{2}$ mitigation when controlled based on cost benefits, and finally Figure6c shows the effect on energy and cost savings when the TES system is operating to maximize $\mathrm{CO}_{2}$ mitigation. The results are presented in the climates that are proved to have potential for the operation of the system (energy savings higher than $1 \mathrm{MJ} /$ day).

The results demonstrate that when the system is controlled based on optimizing energy savings or $\mathrm{CO}_{2}$ mitigation, the benefits of the other outcomes are almost not reduced, being always below $9 \%$ in case of optimizing based on energy and below $2 \%$ in case of 
optimizing based on $\mathrm{CO}_{2}$. On the other hand, when optimizing based on cost reduction, the energy savings and $\mathrm{CO}_{2}$ mitigation are far from their optimum values. The reduction of these two outcomes is very similar for each city which indicates that the optimal performance for energy savings and $\mathrm{CO}_{2}$ mitigation purposes is very similar. Furthermore, these reductions vary among cities between 15\% (Bogota) and 40\% (Madrid). 


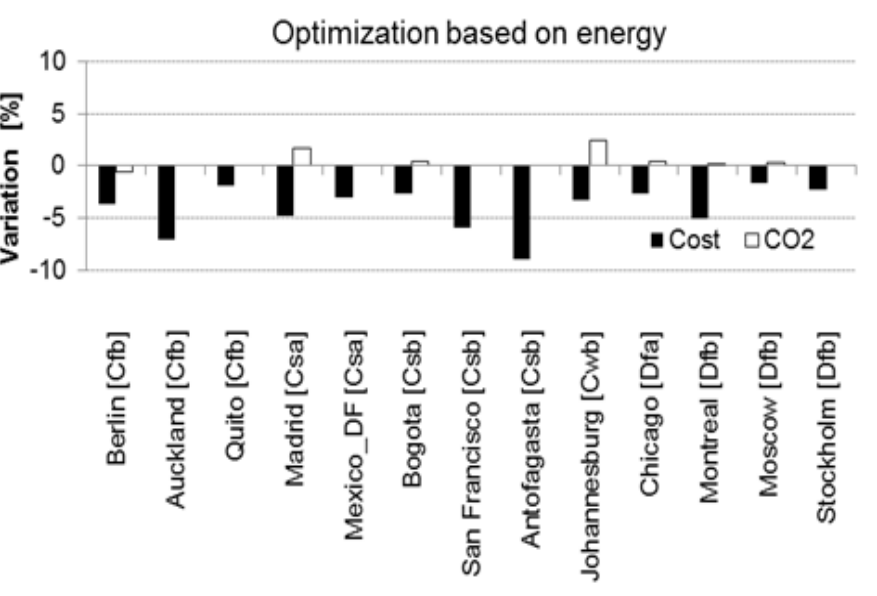

(a)

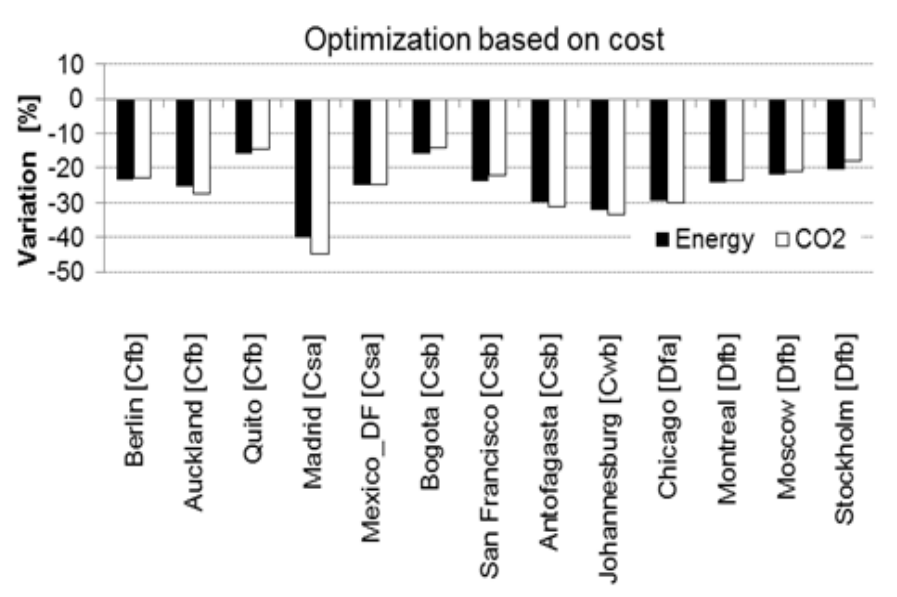

(c)

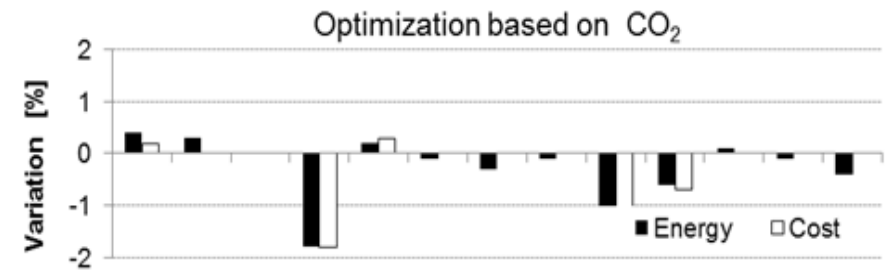

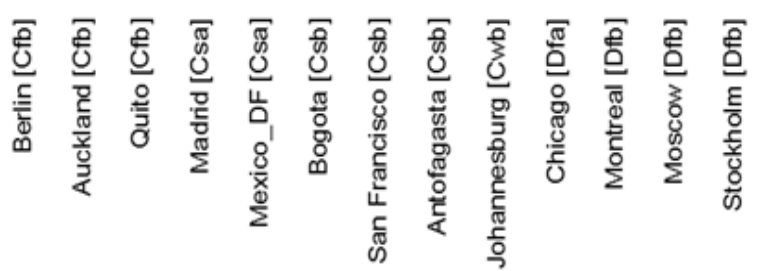

Figure 6. Variation of the different outcomes when optimizing based on other objective. a) Optimization based on Energy, b) Optimization based on Cost, c) Optimization based on $\mathrm{CO}_{2}$ mitigation 


\subsection{Required cost and $\mathrm{CO}_{2}$ investment for cooling production of the system}

So far, our reinforcement learning strategies optimizes one out of three parameters, namely energy, cost and $\mathrm{CO}_{2}$ emissions. At this point we are interested in performing multi-point optimization, obtaining the best cost or $\mathrm{CO}_{2}$ emissions savings that our system can afford for a given energy savings objective. This is achieved by introducing a second state, beside the PCM temperature, that reflects the energy objective.

As previously described, the ventilated facade with PCM before being able to provide any cooling supply, it requires an initial investment to charge the PCM in form of electrical energy to activate the fans. This electrical energy corresponds to a certain cost and $\mathrm{CO}_{2}$ emissions. In this section, the cost and $\mathrm{CO}_{2}$ emissions required to produce different levels of cooling are investigated for the case of Bogota [Csb]. The control of the system was optimized for each one of the summer days, fixing different levels of maximum cooling. Each point corresponds to a double objective optimization result for a given summer period day.

Figure7a plots the cooling supply dependency on cost. It can be seen that the system, as designed, can provide a maximum cooling supply of $1 \mathrm{kWh} /$ day, even increasing the investment. Before arriving to this limit there is a linear relation between cost and cooling production, with a ratio of $36.17 \mathrm{kWh} / €$. Thus mean that the use of the system will be equivalent to use a cooling equipment with $\mathrm{COP}=3$ with an electrical tariff 0.083 $€ /$ kWh.

Moreover, the dependency between the provided cooling supply from the system and the emitted $\mathrm{CO}_{2}$ to achieve this cooling can be observed in Figure7b. Similarly, this design of the system, there is a limit of $0.07 \mathrm{~kg} \mathrm{CO}_{2} /$ day after increasing the amount of $\mathrm{CO}_{2}$ emitted to the atmosphere does not provide more cooling supply. Before achieving this limit, the system presents a ratio of $13.3 \mathrm{kWh} / \mathrm{kg} \mathrm{CO}$. 
(a)

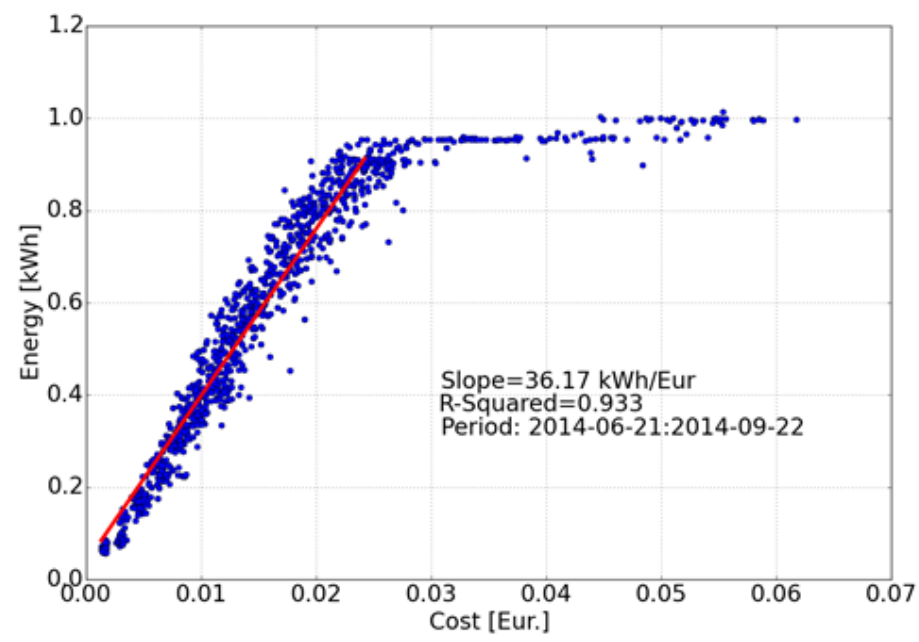

(b)

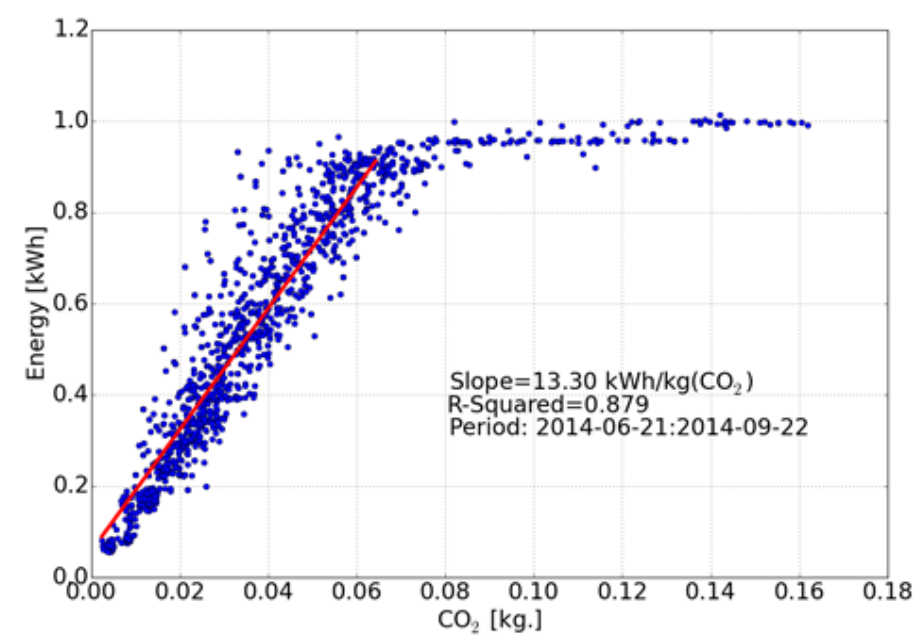

Figure 7. Required cost (a) and $\mathrm{CO}_{2}$ emissions (b) investment for cooling production in Bogota (Csb)

\section{Conclusions}

The present paper evaluates the performance of an active TES system when operated according to a control system based on reinforcement learning techniques. A ventilated facade with PCM in its air chamber is used as a case study. The system is used for cooling purposes, being charged using low temperature at night and providing a cooling supply to the interior of the building during daytime. The algorithm is used to test different control strategies in order to optimize the performance of the system based on energy savings, cost reduction, and $\mathrm{CO}_{2}$ mitigation. These benefits were evaluated in different climates which require cooling according to Köppen-Geiger climate classification [38]. 
In case of energy savings, the use of an appropriate control strategy based on outdoor temperature, increase the energy savings in the cities in which the use of the system is suitable due to its climatic conditions and avoids the possible waste of energy in cities in which the outdoor temperature is not low enough during the night to solidify the PCM. The average energy savings achieved by the automatic mode in comparison to a manual operation of the system is $4.3 \%$. In case of cost savings, similar pattern as in the energy control strategy was observed. In this case the average savings achieved by the system is $7.8 \%$. On the other hand, significantly higher benefits were found when optimizing the control based on $\mathrm{CO}_{2}$ mitigation, showing an average savings of $16.7 \%$.

It is claimed that active TES systems can reduce energy usage, and hence cost and $\mathrm{CO}_{2}$ emissions. The results demonstrated these savings are achieved in all analyzed climates, however, they have also proved that they cannot be optimized at the same time. There is an important reduction in comparison to the optimal value of the energy savings and $\mathrm{CO}_{2}$ mitigation when the system is programmed to increase the cost savings as much as possible.

\section{Acknowledgements}

The work partially funded by the Spanish government (ENE2015-64117-C5-1-R, ENE2015-64117-C5-3-R, TIN2015-71799-C2-2-P and ULLE10-4E-1305). The authors would like to thank the Catalan Government for the quality accreditation given to their research group (2014 SGR 123) and the city hall of Puigverd de Lleida. This project has received funding from the European Commission Seventh Framework Programme (FP/2007-2013) under Grant agreement NoPIRSES-GA-2013-610692 (INNOSTORAGE) and from the European Union's Horizon 2020 research and innovation programme under grant agreement No 657466 (INPATH-TES), and the fund received by the Royal Society of New Zealand. Alvaro de Gracia would like to thank Ministerio de Economia y Competitividad de España for Grant Juan de la Cierva, FJCI2014-19940.

\section{References}


[1] P.H. Shaikh, N.B Mohd Nor, P. Nallagownden, I. Elamvazuthi, T. Ibrahim. A review on optimized control systems for building energy and comfort management of smart sustainable buildings. Renewable and Sustainable Energy Reviews 34 (2014) 409-429.

[2] A. El-Sawi, F. Haghighat, H. Akbari. Assessing long-term performance of centralized thermal energy storage system. Applied Thermal Engineering 62 (2014) 313-321.

[3] K. Menoufi, A. Castell, L. Navarro, G. Pérez, D. Boer, L.F. Cabeza. Evaluation of the environmental impact of experimental cubicles using Life Cycle Assessment: A highlight on the manufacturing phase. Applied Energy 92 (2012) 534-544.

[4] K.O. Lee, M.A. Medina, E. Raith, X. Sun. Assessing the integration of a thin phase change material (PCM) layer in a residential building wall for heat transfer reduction and management. Applied Energy 137 (2015) 699-706.

[5] N. Soares, J.J. Costa, A.R. Gaspar, P. Santos. Review of passive PCM latent heat thermal energy storage systems towards buildings’ energy efficiency. Energy and Buildings 59 (2013) 82-103.

[6] P. Tatsidjodoung, N. Le Pierrès, L. Luo. A review of potential materials for thermal energy storage in building applications. Renewable and Sustainable Energy Reviews 18 (2013) 327-349.

[7] G. Li, S. Qian, H. Lee, Y. Hwang, R. Radermacher. Experimental investigation of energy and exergy performance of short term adsorption heat storage for residential application. Energy 65(2014) 675-691.

[8] W.A. Qureshi, N.K.C. Nair, M.M. Farid. Impact of energy storage in buildings on electricity demand side management. Energy Conversion and Management 52 (2011) 2110-2120.

[9] V. Martin, B. He, F. Setterwall. Direct contact PCM-water cold storage. Applied Energy 87 (2010) 2652-2659.

[10]M. Medrano, M.O. Yilmaz, M. Nogués, I. Martorell, J. Roca, L.F. Cabeza. Experimental evaluation of commercial heat exchangers for use as PCM thermal storage systems. Applied Energy 86 (2009) 2047-2055.

[11]G. Li, Y. Hwang, R. Radermacher. Review of cold storage materials for air conditioning application. International Journal of Refrigeration 35 (2012) 2053-2077.

[12]W.A. Qureshi, N.K.C. Nair, M.M. Farid. Demand side management through efficient thermal energy storage using phase change material. Power Engineering Conference, 2008. AUPEC '08. Australasian Universities.

[13]S. Morgan, K. Moncef. Field testing of optimal controls of passive and active thermal storage. ASHRAE Transactions . 2010, Vol. 116 Issue 1, p134-146. 13p.

[14]M. Farid, W.J. Kong, Underfloor heating with latent heat storage. Proceedings of the Institution of Mechanical Engineers, Part A: Journal of Power and Energy 215 (2001) 601-609.

[15]E.M. Greensfeldera, G.P. Henzea, C. Felsmann, An investigation of optimal control of passive building thermal storage with real time pricing. Journal of Building Performance Simulation, 4 (2011) 91-104. 
[16]J.E. Braun. Reducing energy costs and peak electrical demand through optimal control of building thermal storage. in ASHRAE Transactions. 1990.

[17]F.B. Morris, J.E. Braun, S.J. Treado. Experimental and simulated performance of optimal control of building thermal storage. in ASHRAE Transactions. 1994.

[18]M.D. Ruud, J.W. Mitchell, S.A. Klein. Use of building thermal mass to offset cooling loads. in ASHRAE Transactions. 1990.

[19] M. Kummert, P. André, J. Nicolas. Optimal heating control in a passive solar commercial building. Solar Energy 69 supplement 6 (2000) 103-116.

[20] V.R. Dehkordi, J.A. Candanedo. A model-based predictive control approach for a building cooling system with ice storage. in ASME 2013 Dynamic Systems and Control Conference, DSCC 2013. 2013.

[21] F. Sehar, S. Rahman, M. Pipattanasomporn. Impacts of ice storage on electrical energy consumptions in office buildings. Energy and Buildings 51 (2012) 255-262.

[22] A. Hajiah, M. Krarti. Optimal controls of building storage systems using both ice storage and thermal mass - Part II: Parametric analysis. Energy Conversion and Management 64 (2012) 509515.

[23] A.Hajiah, M. Krarti, Optimal control of building storage systems using both ice storage and thermal mass - Part I: Simulation environment. Energy Conversion and Management 64 (2012) 499-508.

[24] R. Barzin, J.J. Chen, B.R. Young, M.M. Farid. Peak load shifting with energy storage and pricebased control system. Energy 92 Part 3 (2015) 505-514.

[25] R. Barzin, J.J. Chen, B.R. Young, M.M. Farid. Application of PCM underfloor heating in combination with PCM wallboards for space heating using price based control system. Applied Energy 148 (2015) 39-48.

[26] R. Barzin, J.J. Chen, B.R. Young, M.M. Farid. Application of PCM energy storage in combination with night ventilation for space cooling. Applied Energy 158 (2015) 412-421.

[27] R. Barzin, J.J. Chen, B.R. Young, M.M. Farid. Application of weather forecast in conjunction with price-based method for PCM solar passive buildings - An experimental study. Applied Energy 163 (2016) 9-18.

[28]A. de Gracia, C. Fernández, A. Castell, C. Mateu, L.F. Cabeza. Control of a PCM ventilated facade using reinforcement learning techniques. Energy and Buildings 106 (2015) 234-242.

[29] Rubitherm Technologies GmbH, 2014. www.rubitherm.de

[30] A. de Gracia, L. Navarro, A. Castell, A. Ruiz-Pardo, S. Álvarez, L.F. Cabeza. Thermal analysis of a ventilated facade with PCM for cooling applications. Energy and Buildings 65 (2013) 508515.

[31] P. Lamberg, R. Lehtiniemi, A.M. Henell. Numerical and experimental investigation of melting and freezing processes in phase change material storage. International Journal of Thermal Sciences, Vol. 43, 2004, pp. 277-287. 
[32] A. de Gracia, A. Castell, C. Fernández, L.F. Cabeza. A simple model to predict the thermal performance of a ventilated facade with phase change materials. Energy and Buildings 93 (2015) 137-142.

[33] R. Bellman. Dynamic Programming, 1st ed., Princeton University Press, Princeton, NJ, USA, 1957.

[34] R.S. Sutton, A.G. Barto. Introduction to Reinforcement Learning, 1st ed., MIT Press, Cambridge, MA, 1998.

[35]Sistema de información del operador del sistema. Red eléctrica Española. https://www.esios.ree.es/es/pvpc

[36] Red eléctrica Española. https://demanda.ree.es/movil/peninsula/demanda/total;

[37] Instituto para la Diversificación y Ahorro de la Energía (IDAE). Ministerio de industria, turismo y comercio. Gobierno de España. Secretaria general departamento de planificación y estudios. http://www.idae.es/uploads/documentos/documentos_Factores_EP_CO2_2008_d7bc8d56.pdf

[38] M. Kottek, J. Grieser, C. Beck, B. Rudolf, F. Rubel. World map of Köppen-Geigerclimate classification updated, Meteorol. Zeitschrift 15 (3) (2006) 259-263.

[39] U.S. Department of Energy (DOE). EnergyPlus Weather data. https://energyplus.net/weather 